\title{
Method Development and Validation for Detection of Procaterol in Human Urine using Gas Chromatography-Tandem Mass Spectrometry
}

\author{
Shila Jain', Puran Lal Sahu', Srashti Raj², Abhinav Shrivastava', Ashok Kumar Maurya1, Rajiv Kumar \\ Tonk $^{2}$, Kapendra Sahu ${ }^{1, *}$
}

${ }^{1}$ National Dope Testing Laboratory, Ministry of Youth Affairs and Sports (MYAS), Government of India, New Delhi, INDIA.

${ }^{2}$ Delhi Pharmaceutical Sciences and Research University, M.B. Road, New Delhi, INDIA.

\begin{abstract}
Background: A simple, sensitive and accurate method for the determination of procaterol in human urine was developed and validated using Gas Chromatography coupled to tandem mass spectrometry (GC-MS/MS) as per the requirements of World Anti-Doping Agency (WADA) and $\mathrm{ICH}$ guidelines. Methodology: The sample processing includes deconjugation with enzymatic hydrolysis, Solid Phase Extraction (SPE) procedure using XAD2 column and Liquid-liquid Extraction (LLE) followed by the derivatisation using $\mathrm{N}$-methyl trimethylsilysl trifluoroacetamide (MSTFA). Results: The method included a chromatographic run of $17 \mathrm{~min}$ and the calibration curve was linear over the concentration range of $5-40 \mathrm{ng} / \mathrm{mL}$ with a correlation coefficient $(\mathrm{r})$ of 0.98 . The intra- and inter-day assay precision ranged from 0.75 to $0.94 \%$ and 1.2 to $1.70 \%$, respectively. The absolute recovery percentage for procaterol was found to be $83 \%$. The recovery was sufficient to reliable identify the procaterol at or below the level prescribed by WADA ie MRPL 20ng/ $\mathrm{ml}$. The LOQ and LOD was found to be 5 and $3 \mathrm{ng} / \mathrm{ml}$ respectively. Conclusion: A simple and sensitive GC-MS/MS method for quantitative estimation of Procaterol was developed and validated as per the WADA ISL and ICH guidelines. This developed method could be also used for therapeutic drug monitoring purposes.
\end{abstract}

Key words: Procaterol, Validation, ICH Guideline, GC-MS/MS, Doping control, WADA.

\section{INTRODUCTION}

Elite athletes are more susceptible to developing asthma; therefore, the prevalence of asthma and exercise-induced bronchoconstriction is higher than in the background population, making $\beta_{2}$-agonists among the most used drugs in competitive sport. ${ }^{1-3} \mathrm{It}$ is well known that $\beta_{2}$-Adrenoceptor agonists are a useful therapy for asthma. These drugs also exhibit an anabolic effect due to an increase in $\beta_{2}$-adrenoceptor-mediated protein accretion, thus their use by athletes is prohibited by the World Anti-Doping Agency (WADA). WADA code has declared that one should ensure that no prohibited substances should enter in the body and the medication taken should be used in case of illness producing valid Therapeutic use
Exemption certificate (TUE) and that the general safety of the athletes is of utmost importance. ${ }^{3-5}$

In competitive sports, salbutamol, salmeterol and formoterol are now allowed without a Therapeutic Use Exemption (TUE) and clinical proof of asthma or exerciseinduced bronchoconstriction, while other $\beta_{2}$-agonists are allowed if the athlete acquires a TUE. To acquire a TUE, the athlete must meet different medical criteria and have a positive bronchial challenge or reversibility test to $\beta_{2}$-agonists. One of the $\beta_{2}$-agonists that require a TUE is procaterol, which is a commonly prescribed $\beta_{2}$-agonist in Asia and southern Europe. ${ }^{1,2}$
Submission Date: 21-04-2019; Revision Date: 04-09-2019; Accepted Date: 06-11-2019

DOI: 10.5530/ijper.54.1.18 Correspondence: Dr. Kapendra Sahu, National Dope Testing Laboratory, Ministry of Youth Affairs and Sports (MYAS), Government of India, Lodhi Road-110003, New Delhi, INDIA.

Phone: +91-011-24368850 E-mail: kapendra_sahu@ yahoo.com

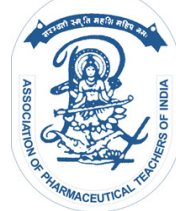

www.ijper.org 
Procaterol is a potent, fast-acting $\beta_{2}$-agonist with a $2(1 \mathrm{H})$-quinolinone chemical skeleton as depicted in Figure 1. It has a long duration of action, used in treatment of asthma by oral or inhalation route. Because of its high intrinsic efficacy and high selectivity for bronchial smooth muscle, procaterol is effective in microgram doses. ${ }^{6}$ However, given the low doses of used procaterol, detection and quantification is difficult in serum and urine. ${ }^{1,6,7}$

In 1980, no sensitive method was available for detection of Procaterol but since 2010, a sensitive and reproducing method was developed which is High performance Liquid Chromatography-Tandem Mass Spectroscopy (HPLC-MS/MS). This method is mainly used for the determination of pharmacokinetic profile of oral Procaterol in urine. By using this method, the detection of parent Procaterol and its metabolite is possible in human urine and serum. The metabolite of Procaterol are measured upto $12 \mathrm{hr}$ after administration but the parent Procaterol is measured upto $24 \mathrm{hr}$ after administration. ${ }^{1,8}$

Several methods have been reported, suggesting separation of $\beta_{2}$-Agonist compounds by using different analytical methods for the determination of $\beta_{2}$-Agonists from biological fluids such as Liquid ChromatographyMass Spectrometry (LC-MS), ${ }^{1,2,9,10}$ Gas Chromatography- Mass Spectrometry (GC-MS $)^{11,12}$ and flow injection analysis coupled with electro generated chemiluminescence (FIA-ECL). ${ }^{13}$

Moreover, the procaterol is metabolized into two metabolites (DM-251 and DM-252) along with the parent drug. However, the metabolites are only measurable up to $12 \mathrm{hr}$ after administration, whereas unchanged procaterol is detectable up to $24 \mathrm{hr}$ after administration. Using this method, the only unchanged procaterol can be measured in urine. Gas Chromatography (GC) is a common and attractive method for the detection and analysis of $\beta_{2}$-Agonist and its analogs compounds, prior to injection a derivatization step is important which makes Gas Chromatography (GC) a more reliable and allow a routine determination and analysis of $\beta_{2}$-Agonist compounds in human urine samples. The purpose of the present study was thus to develop a selective and validated GC-MS/MS method for the determination of procaterol in human urine.

\section{MATERIALS AND METHODS}

\section{Material, Chemical and Standard Solution}

All reagents and chemicals used were of analytical grade or HPLC grade and purchased from different manufac-

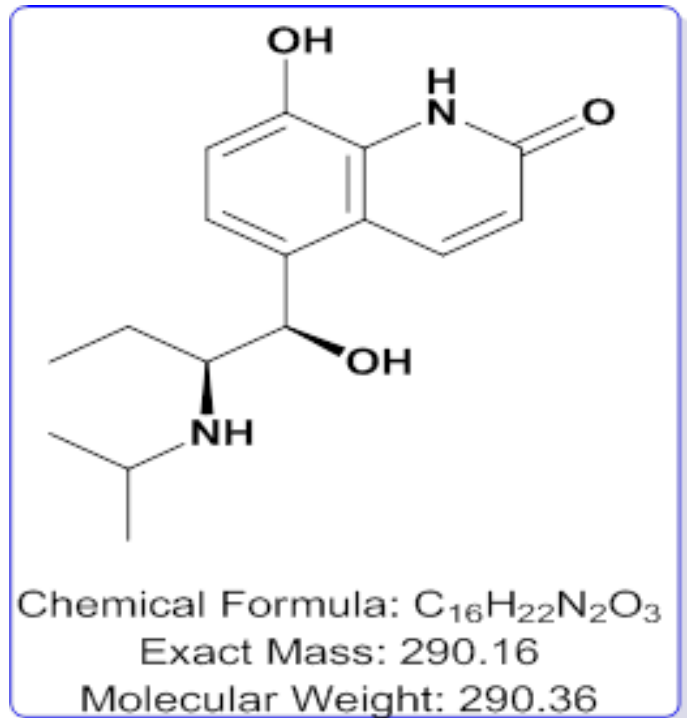

Figure 1: Molecular Structure of Procaterol.

turers. Methanol, Potassium dihydrogen phosphate and Potassium carbonate were obtained from Merck (Mumbai, India), Tertiary Butyl Methyl Ether (TBME) from JT Baker (Phillipburg, USA), $\beta$-Glucuronidase (E. coli) enzyme from Roche Diagnostics Corporation (Indiapolis, USA). XAD2 from Supelco, Acetone, Anhydrous Sodium Sulphate, MSTFA, Iodo-trimethylsilane and Dithioerythitol were obtained from Sigma Aldrich (Mumbai, India). The certified reference standards of steroids and/or their metabolites were obtained from established sources like Sigma-Aldrich, USA, National Measurement Institute, Australia, Cerilliant, USA. The standards Certified Reference Materials (Procaterol HCl and 17a-Methyl Testosterone) were purchased from sigma (Mumbai, India).

\section{Instrumentation and chromatographic conditions}

GC-MS/MS Analysis was performed using Shimadzu QqQ Mass spectrometer TQ 8050, Shimadzu GC-2010 Plus equipped with AOC-20i Automatic Liquid Sampler (ALS). HP Ultra-1 (17m X 220 $\mu \mathrm{m}$ X $0.11 \mu \mathrm{m})$ was used to separate the analyte. Spectral detection was carried out on TQ 8050. The GC-MS/MS data were acquired and processed using GC Labs Solution and Insight GCMS Software.

The temperature program was as follows: the initial temperature was $100^{\circ} \mathrm{C}(0.2 \mathrm{~min})$, increased at $90^{\circ} \mathrm{C} /$ min to $190^{\circ} \mathrm{C}(0.2)$, then at $10^{\circ} \mathrm{C} / \mathrm{min}$ to $225^{\circ} \mathrm{C}$ and at $90^{\circ} \mathrm{C} / \mathrm{min}$ to a final temperature of $310^{\circ} \mathrm{C}$ (held for $0.95 \mathrm{~min})$. The transfer line was set at $280^{\circ} \mathrm{C}$. Helium (Air Liquid) was used as a carrier gas at a flow rate of $0.8 \mathrm{~mL} / \mathrm{min}$ followed by split mode at a ratio $11: 1$. The total run time of the method was found to be less than 17 min. The MS quadrupole temperature was kept at 
$150^{\circ} \mathrm{C}$, while the MS source operated at $230^{\circ} \mathrm{C}$ in Electron Impact (EI) mode, with a solvent delay of $2 \mathrm{~min}$. Data were acquired in the Multiple Reaction Monitoring (MRM) mode, by using this diagnostic transition of the analyte (Procaterol) as shown in Table 1.

\section{Sample preparation}

A $2 \mathrm{~mL}$ aliquot of urine was applied into the XAD2 column and spiked with $50 \mu \mathrm{L}$ of the internal standard mixture. For hydrolysis samples were incubated in an oven at $60^{\circ} \mathrm{C}$ for $1 \mathrm{~h}$ after adding $1 \mathrm{~mL}$ of $0.1 \mathrm{M}$ phosphate buffer solution ( $\mathrm{pH}=7$ ) and $50 \mu \mathrm{L}$ of b-glucuronidase. After adding $250 \mu \mathrm{L}$ of $7 \%$ potassium carbonate solution $(\mathrm{pH}=9-10)$, the mixture was extracted for 10 min with $5 \mathrm{~mL}$ Tert Butyl methyl ether (TBME) by using horizontal shaker. The organic phase was centrifuged for $5 \mathrm{~min}$ at approximately $2000 \mathrm{rpm}$, dried with $\mathrm{Na}_{2} \mathrm{SO}_{4}$ and evaporated under nitrogen at room temperature.

A derivatization procedure of the dried residue using $50 \mu \mathrm{l}$ of MSTFA / IODO -TMS / DTE mixture $(1000 / 2 / 2: \mathrm{v} / \mathrm{v} / \mathrm{w})$ for $30 \mathrm{~min}$ at $60^{\circ} \mathrm{C}$ was used to achieve optimum derivatization efficiency. A $2 \mu \mathrm{L}$ aliquot of this mixture was injected into the GC for analysis.

The MS quadrupole temperature was kept at $150^{\circ} \mathrm{C}$, while the MS source operated at $230^{\circ} \mathrm{C}$ in Electron Impact (EI) mode, with a solvent delay of 2 min. Data were acquired in the Multiple Reaction Monitoring (MRM) mode, by using this diagnostic transition of the analyte (Procaterol) as shown in Table 1.

\section{Validation procedures}

The method was validated in accordance with $\mathrm{ICH}$ guidelines and requirements of WADA ISL [24-25] To establish linearity and range, a stock solution containing $1 \mathrm{mg} / \mathrm{ml}$ drug in ethanol was diluted to yield solutions in the concentration range $5-40 \mathrm{ng} / \mathrm{ml}$ and keeping the injection volume constant $(2 \mu \mathrm{L})$. To assess precision, five injections of three different QC concentrations (8, $15,35 \mathrm{ng} / \mathrm{ml}$ ) were made on the same day and intra-day precision was determined as relative standard deviation. These studies were also repeated on different days to determine inter-day precision. Accuracy was evaluated by fortifying a mixture of decomposed reaction solutions with three known concentrations of the drug and recovery of the added drug was evaluated. The specificity of the method for the drug was established by analyzing human urine samples collected from ten different human to investigate the potential interferences at the GC peak region for analyte and IS using the proposed extraction procedure and chromatographic-MS conditions. The Limits of Detection (LOD) and Quantification (LOQ) were determined experimentally, by analysis of samples spiked with decreasing concentrations of the analytes. LOD was defined as the concentration yielding a signal-to-noise ratio of 3. LOQ was calculated as the smallest concentration of analyte that could be measured with a signal-to-noise ratio of 10 .

\section{Recovery}

Recoveries of the procaterol was determined for human urine by the analysis of six urine samples spiked at Minimum Required Performance Limit (MRPL ie., 20ng/ $\mathrm{ml})$.

\section{RESULTS AND DISCUSSION}

\section{Method development and optimisation}

Initially, the procaterol is allowed to separate in 5:5 ratio, however, the peak shape of analyte was good. The method was developed according to the WADA ISL and ICH guidelines. The developed method could analyse the Procaterol, which is prohibited in sports under the category of $\beta-2$ Agonist. The column allowed separation of analyte in a run time of $23 \mathrm{~min}$. The target compound was identified at $R_{t}$ of 8.4 min of GC elution with solvent delay of $2 \mathrm{~min}$. Initially, the procaterol is allowed to separate in 5:5 ratio and sample volume of $3 \mu \mathrm{l}$, however, the peak shape of analyte was not good. Further, the best separation and acceptable peak shape was achieved at split ratio of 11:1 and sample volume of $2 \mu \mathrm{l}$. The column was injected with $2 \mu \mathrm{l}$ of sample volume through split liner at the split ratio of $11: 1$ at $280^{\circ} \mathrm{C}$ avoiding saturation of liner and ensuring optimal vapor-

\begin{tabular}{|c|c|c|c|c|c|}
\hline \multicolumn{5}{|c|}{ Table 1: Diagnostic MRM transition for procaterol and ISTD. } \\
\hline $\begin{array}{c}\text { Name of } \\
\text { analyte }\end{array}$ & Precursor (m/z) & Product ion & RT & MRM & CE \\
\hline Procaterol & 407 & 318,390 & 8.48 & $407->318$ & 15 \\
& & & & $407->390$ & 20 \\
\hline $\begin{array}{c}\text { 17 a-methyl } \\
\text { testosterone } \\
\text { (ISTD) }\end{array}$ & 446 & 301,195 & 16.00 & $446->301$ & 15 \\
\hline
\end{tabular}




\begin{tabular}{|c|c|c|c|c|}
\hline \multicolumn{5}{|c|}{ Table 2: Results from study of precision and accu- } \\
racy. \\
\hline $\begin{array}{c}\text { Quality } \\
\text { control }\end{array}$ & $\begin{array}{c}\text { Nominal } \\
\text { conc. } \\
\text { (ng/ml) }\end{array}$ & $\begin{array}{c}\text { Mean } \pm \text { SD } \\
(\boldsymbol{n}=3)\end{array}$ & $\begin{array}{c}\text { Accuracy } \\
(\%)^{\mathbf{a}}\end{array}$ & $\begin{array}{c}\text { Precision } \\
(\%)^{\mathbf{b}}\end{array}$ \\
\hline \multicolumn{5}{|c|}{ Intraday precision } \\
\hline QC-low & 8 & $8.911 \pm 0.083$ & $111 \%$ & 0.931 \\
\hline $\begin{array}{c}\text { QC- } \\
\text { medium }\end{array}$ & 15 & $13.129 \pm 0.125$ & $87 \%$ & 0.952 \\
\hline QC-high & 35 & $33.93 \pm 0.256$ & $96 \%$ & 0.754 \\
\hline \multicolumn{5}{|c|}{ Inter day precision } \\
\hline QC-low & 8 & $8.252 \pm 0.141$ & $103 \%$ & 1.700 \\
\hline $\begin{array}{c}\text { QC- } \\
\text { medium }\end{array}$ & 15 & $13.091 \pm 0.139$ & $87 \%$ & 1.060 \\
\hline QC-high & 35 & $33.141 \pm 0.355$ & $94 \%$ & 1.071 \\
\hline
\end{tabular}

${ }^{a}$ Calculated as (mean determined concentration/nominal concentration) $\times 100$ ${ }^{\mathrm{b}}$ Expressed as \% RSD (SD/mean)

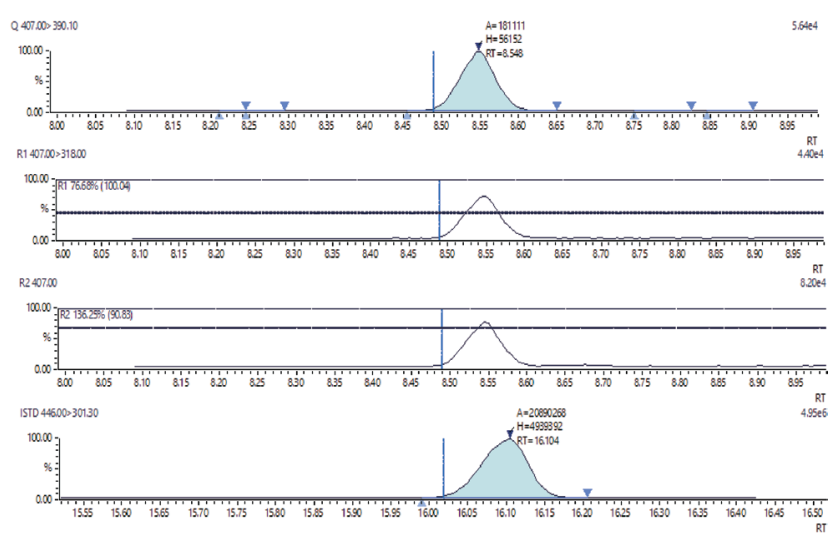

Figure 2: Representative SRM ion chromatograms of prohibited substances in human urine.

ization of the analyte of interest. Detection was performed by positive ion electron impact spray ionization (EI) in Multiple Reaction Monitoring (MRM) mode. The best separation and stability were achieved for the above said conditions. Determination and optimization of the mass spectrometric condition were done in a multistep process. First a full scan spectrum was obtained for every derivatised compound. After selection of a suitable precursor ion, full product scan mass spectra were acquired at different collision energies. Suitable product ion and optimization of the collision energy was then performed both on reference standard and extract from spiked urine samples. The Multiple Reaction Monitoring (MRM) diagnostics ions are shown in Figure 2.

\section{Validation}

The calibration curve was constructed using five calibration standards (viz., 5-40 ng/mL). The calibration standard curve had a reliable reproducibility over the standard concentrations across the calibration range.
The calibration curve was prepared by determining the best fit of peak-area ratios (peak area analyte/peak area IS) versus concentration and fitted to the $y=m x+c$ using weighing factor $(1 / \mathrm{X})$. The regression $\left(r^{2}\right)$ and its equation were found to be 0.98 and $y=0.197+0.0002$, respectively. Accuracy and precision data for intra- and inter-day samples are ranged from $87-111 \%$ and 0.75 $1.7 \%$, respectively. The assay values on both the occasions (intra- and inter-day) were found to be within the accepted variable limits as given in Table 2 . The percentage recovery for procaterol at Minimum Required Performance Limit (MRPL ie., $20 \mathrm{ng} / \mathrm{ml}$ ) was found to be $83 \%$. The recovery was sufficient to reliable identify the procaterol at or below the level prescribed by WADA ie MRPL 20ng/ml. The LOQ and LOD was found to be 5 and $3 \mathrm{ng} / \mathrm{ml}$ respectively.

\section{CONCLUSION}

A simple and sensitive GC-MS/MS method for quantitative estimation of Procaterol was developed and validated as per the WADA ISL and ICH guidelines. This method was specific, accurate and reproducible for Procaterol. The estimated run time of the developed method is $17 \mathrm{~min}$ at constant pressure. The current method would get enhanced by combining the triple quadrupole with Gas Chromatography, thereby can greatly improve the detection capabilities and minimising false detection of target substance in complex matrix. The method would be successfully applied to the screening and confirmation analysis of dope test samples. Further, the extension of this work would be on the differentiation of results of Procaterol analysis in human urine due to presence of confounding/interfering factors. Further, studies are in progress to access the effectiveness of this method for the detection of other $\beta_{2}$-Agonist.

\section{ACKNOWLEDGEMENT}

The author wishes to acknowledge the Ministry of Youth Affairs and Sports, Govt. of India for their continuous support.

\section{CONFLICT OF INTEREST}

The authors declare no conflict of interest.

\section{ABBREVIATIONS}

WADA: World Anti-Doping Agency; TUE: Therapeutic Use Exemption certificate; HPLC: High Performance Liquid Chromatography; GC-MS: Gas 
Chromatography- mass spectrometry; SPE: Solid Phase Extraction; LC-MS: Liquid chromatography mass spectrometry; TBME: Tertiary Butyl methyl ether; $\mathbf{R}_{\mathrm{T}}$ : Retention time.

\section{REFERENCES}

1. Nanna K, Vibeke B, Sebastian R, Peter H, Morten H. Pharmacokinetics of nebulized and oral procaterol in asthmatic and non-asthmatic subjects in relation to doping analysis. Drug Test Analysis. 2016;8(10):1056-64.

2. Peters RJB, Oosterink JE, Stolker AA, Nielen MWF. Generic sample preparation combined with high-resolution liquid chromatography-time-offlight mass spectrometry for unification of urine screening in doping-control laboratories. Anal Bioanal Chem. 2010;396(7):2583-98.

3. Sahu K, Patel P, Karthikeyan C, Trivedi P. The ICH Guidance in Practice: Stress degradation studies on irbesartan and development of a validated stability-indicating UPLC Assay. Acta Chromatographica. 2010;22(2):189205.

4. Ahi S, Sahu K, Nasare M, Singh S, Beotra A, Jain S. Quantitative estimation of alcohol marker ethyl glucuronide (EtG) in human hair by LC-MS/MS: An Application Towards Doping Control and Forensic Science. Current Chromatography. 2018;5(2):112-6.

5. Choo JJ, Horan MA, Little RA, Rothwell NJ. Anabolic effects of clenbuterol on skeletal muscle are mediated by b2-adrenoceptor activation. Am J Physiol. 1992; 263(1):50-6.
6. World Anti-Doping Agency (WADA). The Prohibited list January. 2019.

7. Backer V, Lund T, Dederson L. A review on pharmaceutical treatment of asthma symptoms in elite athletes-doping or therapy. Sc and Journal of Medicine and Science in Sports. 2007;17(6):615-22.

8. Kobayashi H, Masuda M, Kashiyama E, Koga N, Yasuda Y, Shibutani T, et al. Pharmacokinetic study of the oral administration of procaterol hydrochloride hydrate 50 microg in healthy adult Japanese men. International Journal of Clinical Pharmacology and Therapeutics. 2010;48(11):744-50.

9. $\mathrm{Qu} \mathrm{CH}, \mathrm{Li} \mathrm{XL}$, Zhang L, Xi CX, Wang GM, Li NB. Simultaneous determination of cimaterol, salbutamol, terbutaline and ractopamine in feed by solid phase extraction coupled to ultra-performance liquid chromatography. Chromatographia. 2011;73(3-4):243-9.

10. Hu Y, Liu R, Li Y, Li G. Investigation of ractopamine-imprinted polymer for dispersive solid-phase extraction of trace $\beta$-agonists in pig tissues. Journal of Separation Science. 2010;33(13):2017-25

11. Morra V, Davit P, Capra P, Vincenti M, DiStilo A, Botrè F. Fast gas chromatographic/mass spectrometric determination of diuretics and masking agents in human urine: Development and validation of a productive screening protocol for antidoping analysis. Journal of Chromatography A. 2006;1135(2):219-29.

12. Damasceno L, Ventura R, Ortuño J, Segura J. Derivatization procedures for the detection of $\beta_{2}$-agonists by gas chromatographic/mass spectrometric analysis. Journal of Mass Spectrometry. 2000;35(11):1285-94.

13. Kong D, Jiang L, Liu Y, Wang Z, Han L, Rixin Lv, et al. Electrochemical investigation and determination of procaterol hydrochloride on poly (glutamic acid)/carboxyl functionalized multiwalled carbon nanotubes/polyvinyl alcohol modified glassy carbon electrode. Talanta. 2017;174:436-43.

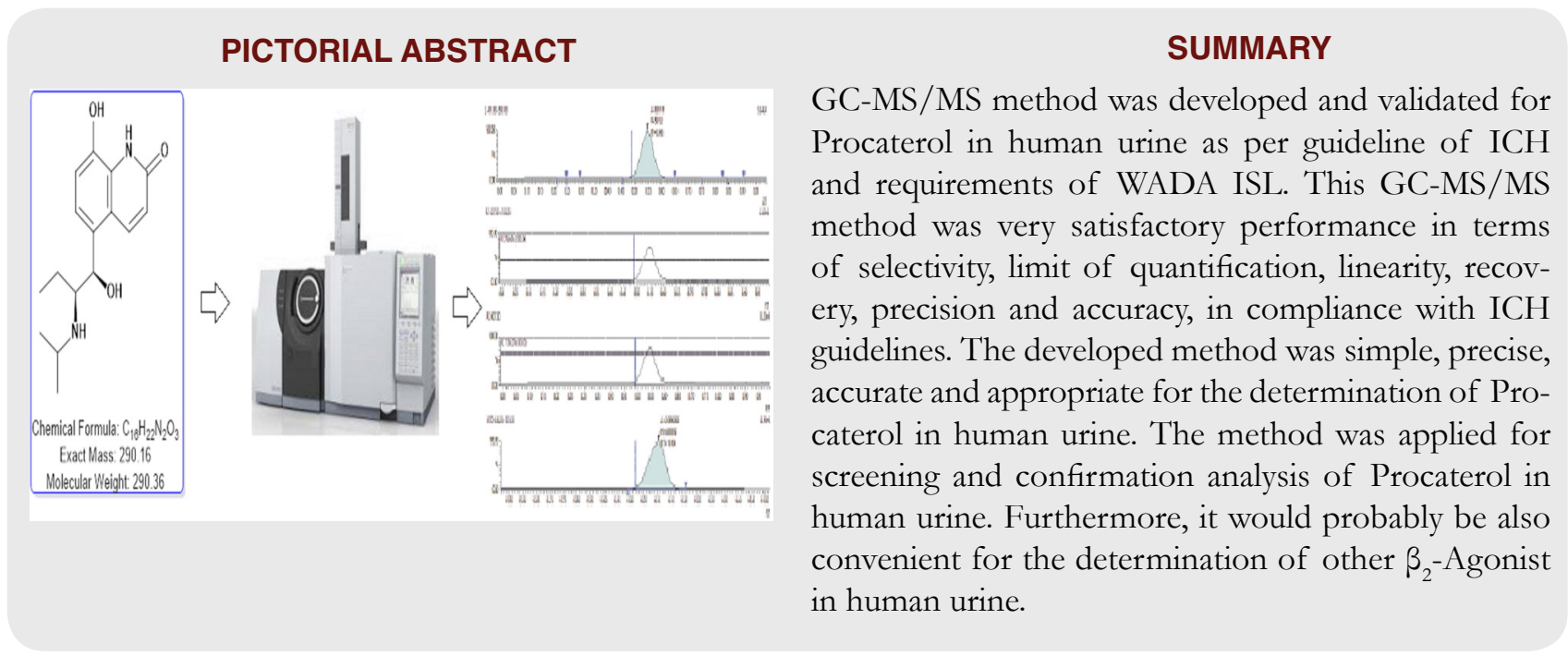

Cite this article: Jain S, Sahu PL, Raj S, Shrivastava A, Maurya AK, Tonk R, et al. Method Development and Validation for Detection of Procaterol in Human Urine using Gas Chromatography-Tandem Mass Spectrometry. Indian J of Pharmaceutical Education and Research. 2020;54(1):150-4. 